Measuring economic outcomes of alcohol treatment using the Economic Form 90

By: Jeremy W. Bray, Gary A. Zarkin, William R. Miller, Debanjali Mitra, Daniel R. Kivalahan, Daniel J. Martin, David J. Couper, and Ron A. Cisler

Bray, J. W., Zarkin, G. A., Miller, W. R., Mitra, D., Kivlahan, D. R., Martin, D. J., Couper, D. J., \& Cisler, R. A. (2007). Measuring economic outcomes of alcohol treatment using the economic form 90. Journal of Studies on Alcohol and Drugs, 68(2), 248-255.

Made available courtesy of Rutgers Center of Alcohol Studies: http://www.jsad.com/

***@ C Rutgers Center of Alcohol Studies. Reprinted with permission. No further reproduction is authorized without written permission from Rutgers Center of Alcohol Studies.***

Abstract:

Objective: This article assesses the ability of the economic outcome measures in the Economic Form 90 to detect differences across levels of alcohol dependence as measured by the Alcohol Dependence Scale. Method: We used baseline data from the Combining Medications and Behavioral Interventions (COMBINE) Study, a large, multisite clinical trial, to assess the extent to which the economic items on the Economic Form 90 instrument can detect differences across levels of alcohol dependence. Results: After adjusting for differences in demographic characteristics, the Economic Form 90 can detect significant differences across a range of dependence seventy levels for the economic outcomes of inpatient medical care, emergencydepartment medical care, behavioral health care, being on parole or probation, and missed workdays, conditional on being employed. We did not detect significant differences across dependence severity for employment status, outpatient medical care, other criminal justice involvement, or motor vehicle accidents. Conclusions: The Economic Form 90 can identify differences in many economic outcomes associated with differing levels of alcohol dependence. This suggests that the Economic Form 90 may be useful in assessing changes in economic outcomes that result from changes in alcohol dependence.

Keywords: COMBINE Study | Economic Form 90 | economic outcomes | alcohol dependence

Article:

***Note: Full text of article below 


\title{
Measuring Economic Outcomes of Alcohol Treatment Using the Economic Form 90*
}

\author{
JEREMY W. BRAY, PH.D., ${ }^{\dagger}$ GARY A. ZARKIN, PH.D., WILLIAM R. MILLER, PH.D., ${ }^{\dagger}$ DEBANJALI MITRA, M.A., \\ DANIEL R. KIVLAHAN, PH.D., ${ }^{\dagger}$ DANIEL J. MARTIN, PH.D., ${ }^{\dagger}$ DAVID J. COUPER, PH.D., ${ }^{\dagger}$ AND RON A. CISLER, PH.D. ${ }^{\dagger}$
}

RTI International, 3040 Cornwallis Road, Research Triangle Park, North Carolina 27709

\begin{abstract}
Objective: This article assesses the ability of the economic outcome measures in the Economic Form 90 to detect differences across levels of alcohol dependence as measured by the Alcohol Dependence Scale. Method: We used baseline data from the Combining Medications and Behavioral Interventions (COMBINE) Study, a large, multisite clinical trial, to assess the extent to which the economic items on the Economic Form 90 instrument can detect differences across levels of alcohol dependence. Results: After adjusting for differences in demographic characteristics, the Economic Form 90 can detect significant differences across a range of dependence severity levels for the eco-
\end{abstract}

nomic outcomes of inpatient medical care, emergency-department medical care, behavioral health care, being on parole or probation, and missed workdays, conditional on being employed. We did not detect significan differences across dependence severity for employment status, outpatient medical care, other criminal justice involvement, or motor vehicle accidents. Conclusions: The Economic Form 90 can identify differences in many economic outcomes associated with differing levels of alcohol dependence. This suggests that the Economic Form 90 may be useful in assessing changes in economic outcomes that result from changes in alcohol dependence. (J. Stud. Alcohol Drugs 68: 248-255, 2007)
$\mathrm{P}$ ARTLY IN RESPONSE TO THE TREMENDOUS social costs of alcohol dependence, new pharmacotherapies have been developed (Anton and Swift, 2003) and important advances have been made in developing behavioral interventions designed to treat alcohol abuse and dependence (Hester and Miller, 2003; Miller et al., 2001; Project MATCH Research Group, 1998). Concomitant with the development of new therapies, pressures have increased to identify therapies that are not only efficacious but also costeffective. Much of this pressure has been driven by managed care, which has placed a premium on economic studies that assess whether the clinical and economic outcomes of new pharmaceutical and behavioral therapies justify their costs. Without cost-effectiveness studies, managed care or-

Received: February 8, 2006. Revision: September 15, 2006.

*This research was supported by National Institute on Alcohol Abuse and Alcoholism (NIAAA) grant I-R01-AA12788. This article does not necessarily represent the policies or the positions of the NIAAA, and no official endorsement by NIAAA is intended or should be inferred. The authors have no financial or personal relationships that constitute a conflict of interest for this research.

${ }^{\dagger}$ Correspondence may be sent to Jeremy W. Bray at the above address or via email at: bray@rti.org. William R. Miller is with the Department of Psychology, University of New Mexico, Albuquerque, NM. Daniel R. Kivlahan is with the Center of Excellence in Substance Abuse Treatment and Education, Veterans Affairs Puget Sound, Seattle, WA. Daniel J. Martin is with the Substance Abuse Treatment Unit, Yale University, New Haven, CT. David J. Couper is with the Department of Biostatistics, University of North Carolina at Chapel Hill, Chapel Hill, NC. Ron A. Cisler is with the Center for Urban Population Health, University of Wisconsin-Milwaukee, University of Wisconsin School of Medicine and Public Health, Aurora Sinai Medical Center, Milwaukee, WI. ganizations may be reluctant to include pharmacotherapies for alcohol dependence treatment on their formularies of approved drugs.

Despite the increased attention to the cost and cost-effectiveness of alcohol dependence treatment, few studies provide researchers with guidance on how best to measure the associated economic burden among patients seeking treatment or the effect of treatment on economic outcomes. Although formal economic cost studies have been conducted on alcohol treatments (e.g., Cisler et al., 1998; Holder et al., 2000; Zarkin et al., 2003, 2005), these studies focus on identifying and monetizing the resources used in direct service delivery and do not provide information on the effect of alcohol treatment on future societal costs. Other studies have relied on administrative data to measure the effect of alcohol treatments on relevant economic outcomes, but these studies have typically limited their analyses to the single economic outcome of health care use (e.g., Holder and Blose, 1986; Kane et al., 2004). Because many economic outcomes other than health care use are potentially affected by alcohol treatment, and in light of increasing concerns over patient privacy that may limit future access to administrative data, researchers must rely increasingly on selfreport instruments for capturing information on the economic outcomes of alcohol treatment.

In this article, we use baseline data from the Combining Medications and Behavioral Interventions (COMBINE) Study (COMBINE Study Research Group, 2003) to assess the ability of the economic outcome measures in the Economic Form 90 to detect differences across levels of alcohol dependence as measured by the Alcohol Dependence 
Scale (ADS). The Economic Form 90, also known as the Form 90 At Intake Revised/Economic Data, or Form 90 $\mathrm{AIR} / \mathrm{ED}$, is available on request from the corresponding author. The Economic Form 90 is a modified version of the Form 90 family of instruments that collects alcohol-use and economic-outcome data for alcohol treatment studies (Miller and Del Boca, 1994; Scheurich et al., 2005; Tonigan et al., 1997). The Economic Form 90 was designed to measure changes from baseline on key economic outcomes following treatment for alcohol dependence. These changes can then be combined with information on the social cost of economic outcomes and with information on the cost of the treatment itself to support cost-effectiveness and costbenefit analyses.

\section{The COMBINE Study}

The COMBINE Study is a multicenter, randomized, controlled clinical trial sponsored by the National Institute on Alcohol Abuse and Alcoholism. It is the first national study to investigate whether combinations of pharmacotherapy (naltrexone [Revia] and acamprosate [Campral]) and behavioral therapies are superior to monotherapy in treating alcohol dependence. A total of 1,383 subjects across 11 sites participated in the study (COMBINE Study Research Group, 2003) and were randomized into nine possible treatment groups. Treatment lasted for 16 weeks, with a followup period of 1 year. Results for the primary clinical outcomes from COMBINE are available in Anton et al. (2006). An ancillary cost-effectiveness study is following subjects from nine sites for 2 additional years.

\section{Background on the Form 90}

The Form 90 is the primary instrument for assessing the alcohol consumption patterns of individuals participating in COMBINE. The Form 90 is a reliable instrument for collecting alcohol use data in alcohol treatment studies (Miller and Del Boca, 1994; Scheurich et al., 2005; Tonigan et al., 1997). The form was first developed for Project MATCH (Matching Alcohol Treatments to Client Heterogeneity) to characterize daily alcohol use of treatment-seeking adults, and its reliability was established after being evaluated in two test-retest studies using Project MATCH data (Tonigan et al., 1997). The Form 90 has been widely used in clinical trials since then (Sobell and Sobell, 2003). The form has been successfully used to gather a broad range of drinking data not only from the general adult population in the United States but also from adolescents (Dennis et al., 2004) and the adult population in Germany (Scheurich et al., 2005).

The Form 90 is a structured interviewer-administered instrument with tested reliability that yields quantitative data through a detailed, comprehensive assessment of daily al- cohol use, weekly patterns, and atypical episodes of drinking using a calendar-based Timeline Followback method. It has baseline and follow-up versions and brief versions for reluctant subjects and telephone interviews. In addition, the Form 90 has been modified to acquire detailed information on illicit drug use (Westerberg et al., 1998). Because interviewers use the calendar follow-back method to assist subject recall, other important nondrinking outcome measures can also be collected using the Form 90 .

\section{The Economic Form 90}

We developed the Economic Form 90 to capture the patient-level cost and outcome data necessary to conduct an economic evaluation of COMBINE. In addition to all questions in the original Form 90, the Economic Form 90 includes questions assessing patient time costs and key drivers of the social costs of alcohol dependence. The primary goal of the modified instrument is to include the economic domains that contribute to the majority of the social costs of alcohol dependence, without being so comprehensive as to be prohibitively burdensome to respondents. Because alcohol dependence can have economic costs on almost all facets of individuals' lives, we relied on studies of the social costs of alcohol abuse and dependence to limit the economic cost domains included in the Economic Form 90 to those most likely to capture the majority of economic costs. Based on previous research on the social costs of alcohol abuse (Harwood et al., 1998), the four major economic domains included in the Economic Form 90 are health care use, criminal justice involvement, labor market outcomes, and motor vehicle accidents. Although these domains may omit other potentially important social cost domains, we felt they achieved a reasonable balance between capturing the data necessary to conduct a rigorous cost-effectiveness analysis and keeping respondent burden to a manageable level.

The patient time costs collected by the Economic Form 90 measure the time spent by patients traveling to and engaging in the COMBINE therapies. Because COMBINE used a randomized design, it is unlikely that these time costs are related to the baseline severity of alcohol dependence and more likely that they are related to the therapies to which patients were randomly assigned. Furthermore, because we analyzed baseline data collected at randomization, the data do not capture any actual intervention visits.

Similar to many self-report questionnaires, health careuse questions in the Economic Form 90 capture data on whether an individual had inpatient, outpatient, or emergency department visits and, if so, the number of days of visits for each of these categories. The form also records the number of days of health care related to alcohol, drug, and mental health (ADM) issues. Although more detailed categorizations of health care use might be preferred, we 
chose these relatively standard categorizations because we were concerned that respondents would have difficulty recalling and classifying events within more detailed categories. The criminal-justice domain includes questions on the occurrence and number of arrests (by type of arrest), number of court appearances, visits to parole/probation officer, and nights in jail. The labor-market domain includes employment status, legal income from various sources, and workdays missed because of alcohol. The motor vehicle accidents domain consists of a single item regarding the number of motor vehicle accidents in the period.

The Economic Form 90 also asks questions on participation in Alcoholics Anonymous or self-help programs as well as medications taken, but these outcomes were not examined in this analysis. The role of self-help programs in the social costs of alcohol dependence is unclear. On the one hand, self-help programs represent a patient-determined treatment cost and thus are a cost of treatment, not an economic outcome of treatment. On the other hand, ongoing participation in self-help programs may be a factor in longterm recovery; therefore, these programs can be viewed as a critical mediating factor in the long-term success of treatment. Given the unclear role of self-help programs in the economic benefits of alcohol treatment, we did not include participation in such programs in this analysis. We also did not examine medication costs in this analysis. Although medication costs account for an increasing component of overall health care costs, preliminary analysis of the medication use data indicated that patients are prone to erroneous reporting of medications, and broad medication-use categories do not provide an accurate cost estimate because of the large variation in medication prices.

Although the Economic Form 90 uses a calendar-based Timeline Followback method to capture alcohol consumption data, it does not assess economic domains on the calendar. Because the economic outcomes are considered secondary to the main clinical outcomes captured by the Economic Form 90, we consciously limited the respondent burden associated with the economic outcome questions by asking respondents to report total events during the period rather than assign specific events to specific days on the calendar. Nonetheless, the calendar-based method used to collect drinking data may improve recall of other specific events during the assessment period, thereby improving the quality of the self-reported economic outcome data.

\section{Method}

We used baseline data from COMBINE to assess the extent to which the economic items in the Economic Form 90 differ among individuals, based on levels of alcohol dependence as measured by the ADS. The ADS is a selfreport instrument that provides a quantitative measure of the severity of alcohol dependence, consistent with the con- cept of the alcohol dependence syndrome (Skinner and Allen, 1982; Skinner and Horn, 1984). The 25-item instrument (total scores range from 0 to 46) covers alcohol withdrawal symptoms, impaired control over drinking, awareness of a compulsion to drink, and salience of drink-seeking behavior. The ADS is widely used as a research and clinical tool, and studies have found the instrument to be reliable and valid (Maisto et al., 2003; Skinner and Allen, 1982; Skinner and Horn, 1984).

The baseline data consisted of individual-level responses to the questions on the Economic Form 90; key demographic characteristics from the COMBINE demographic questionnaire, such as age, gender, marital status, race/ethnicity, and years of education; and respondents' total scores from the ADS instrument. Of the 1,383 eligible subjects that were randomized into the study, seven subjects had more than five missing values on the individual questions in the ADS questionnaire and were excluded from the analysis. For individuals who had fewer than five missing items, the rounded value of the mean of the nonmissing items was imputed for the missing items (see Saxon et al. [2005] for more details on the imputation methods used with ADS). An additional 29 subjects were excluded because of missing values on the key demographic measures. The final analysis sample consisted of 1,347 subjects.

To simplify reporting and interpretation of the relationship between economic outcomes and levels of alcohol dependence, we categorized subjects into four levels of dependence based on the approximate quartile of the distribution of the continuous ADS score: A score of 1-11 indicates a low level of dependence, 12-16 indicates moderate or intermediate dependence, 17-21 indicates substantial dependence, and 22-46 indicates severe dependence (Saxon et al., 2005). Prior analyses of dependence categories based on different quartile cut points in different samples show concurrent validity as a measure of dependence severity, based on significant and large linear trends from Quartile 1 to 4 , reflecting more drinks per drinking day on the Form 90, higher total scores for alcohol-related adverse consequences on the Drinker Inventory of Consequences (Miller et al., 1995), more craving on the Obsessive-Compulsive Drinker Scale (Anton et al., 1995), and substantially higher rates of prior alcohol treatment. Analyses using the same data and ADS quartile cut points used here confirm the use of ADS quartiles as categorical measures of severity of alcohol dependence (Saxon et al., 2005).

For the health care-use domain, we examined nights in a hospital, emergency department visits, outpatient visits, and ADM-related visits. For the criminal-justice domain, we included any involvement with the criminal-justice system and also divided criminal-justice involvement into ADM-related arrests (driving under the influence and arrests for drunken or disorderly conduct), non-ADM-related arrests, court appearances, visits to parole or probation officers, 
and overnight jail or incarceration. For the labor-market domain, we examined current employment status and, conditional on employment, days of work missed because of alcohol. Finally, we examined whether respondents had any motor vehicle accidents. We coded each of these outcomes into a $0 / 1$ dichotomous variable, where 1 indicates at least one occurrence of the outcome within the 90-day period ending on the date of the respondent's last drink. The number of occurrences of each outcome was not analyzed because of very low counts for any one outcome within a 90-day period. (We anticipate higher counts when the economic outcomes are accumulated across a longer time frame.) We tested for significant associations between the dichotomous economic outcomes and the ADS score categories using chi-square tests of association.

To control for the possible confounding effects of demographic differences across the respondents in the ADS score categories, we also conducted logistic regression analysis of the ADS score categories on each of the dichotomous economic outcomes. The specification of the logistic model is:

$$
\begin{aligned}
& \text { Prob }(Y=1)=f\left(\beta_{0}+\beta_{1} \text { Age }+\beta_{2} \text { Male }+\beta_{3}\right. \text { Married } \\
& \left.+\beta_{4} \text { Race }+\beta_{5} \text { Ed }+\beta_{6} \text { Mod }+\beta_{7} \text { Subs }+\beta_{8} \text { Sev }\right),
\end{aligned}
$$

where $Y$ is an indicator variable for the occurrence of the economic event of interest; Age is continuous age in years; Male is an indicator for males; Married is an indicator for married; Race is a vector of indicators for race; Ed is continuous years of education; and Mod, Subs, and Sev are indicators for the second, third, and fourth ADS score cat- egories, respectively, with the first quartile indicator as the referent. The $B s$ are coefficients to be estimated; $\beta_{6}$ through $B_{8}$ capture the association between the severity of dependence as measured by the ADS categories and any occurrence of each economic variable, and the exponential of each coefficient is the associated odds ratio (OR).

\section{Results}

Table 1 presents the demographic characteristics and mean ADS total score of the sample, by levels of dependence. Compared with those with lower levels of dependence, participants with severe dependence were significantly younger and less likely to be married. Those with low levels of dependence also had significantly more years of education. Dependence levels, however, did not vary significantly by gender or race/ethnicity.

Table 2 shows the proportion of respondents with at least one occurrence of each health care outcome for the four categories of dependence severity and the associated adjusted ORs (relative to the lowest category). Adjusted ORs are based on the results of Equation 1 and control for demographic characteristics. For almost all health care outcomes, we found a positive and significant correlation between the occurrence of the outcome and the severity of dependence, based both on a chi-square test of association and on adjusted ORs derived from the logistic analysis. The lone exception was outpatient health care visits: We found no significant relationship between dependence and outpatient visits. For outpatient ADM visits, we found no significant association based on the chi-square test, but we

\begin{tabular}{|c|c|c|c|c|}
\hline \multirow[b]{2}{*}{$\begin{array}{l}\text { Demographic } \\
\text { characteristic }\end{array}$} & \multicolumn{4}{|c|}{ Level of dependence } \\
\hline & $\begin{array}{c}\text { Low } \\
(1-11) \\
(n=309)\end{array}$ & $\begin{array}{l}\text { Moderate } \\
(12-16) \\
(n=352)\end{array}$ & $\begin{array}{l}\text { Substantial } \\
(17-21) \\
(n=335)\end{array}$ & $\begin{array}{c}\text { Severe } \\
(22-46) \\
(n=351)\end{array}$ \\
\hline ADS score, mean (SD) & $8.269(2.388)$ & $14.108(1.414)$ & $18.908(1.382)$ & $27.182(4.979)$ \\
\hline Age, mean (SD) years* & $49.003(10.166)$ & $45.321(10.116)$ & $42.301(9.402)$ & $41.464(9.539)$ \\
\hline Male, \% & 70.6 & 68.8 & 65.1 & 71.8 \\
\hline \multicolumn{5}{|l|}{ Marital status, $\% *$} \\
\hline Single & 20.4 & 23.6 & 30.7 & 35.0 \\
\hline Married ${ }^{a}$ & 52.8 & 54.8 & 44.5 & 34.2 \\
\hline Separated & 4.9 & 3.4 & 3.6 & 6.0 \\
\hline Divorced & 20.7 & 17.0 & 20.9 & 24.2 \\
\hline Widow(er) & 1.3 & 1.1 & 0.3 & 0.6 \\
\hline \multicolumn{5}{|l|}{ Race } \\
\hline Black & 7.8 & 6.8 & 7.8 & 9.1 \\
\hline Hispanic American & 9.4 & 10.5 & 11.3 & 14.5 \\
\hline Non-Hispanic white & 78.0 & 79.8 & 76.7 & 71.8 \\
\hline Other race & 4.9 & 2.8 & 4.2 & 4.6 \\
\hline Education, mean & $153110545)$ & $14844(2034)$ & $14313(2607)$ & $13832(2580)$ \\
\hline
\end{tabular}

TABLE 1. Sample characteristics, by Alcohol Dependence Scale (ADS) quartile

Notes: ADS dependence categories are based on COMBINE quartiles. ${ }^{a}$ Married includes cohabiting or living with a partner.

*Indicates significant differences across levels of dependence at the .05 level ( $F$ test for continuous variables, chi-square test for binary variables). 
TABLE 2. Sample proportion and odds ratios of health care outcomes, by Alcohol Dependence Scale (ADS) categories

\begin{tabular}{|c|c|c|c|c|}
\hline \multirow[b]{2}{*}{ Outcome } & \multicolumn{4}{|c|}{ Level of dependence } \\
\hline & $\begin{array}{c}\text { Low } \\
(1-11) \\
(n=309)\end{array}$ & $\begin{array}{c}\text { Moderate } \\
(12-16) \\
(n=352)\end{array}$ & $\begin{array}{c}\text { Substantial } \\
(17-21) \\
(n=335)\end{array}$ & $\begin{array}{c}\text { Severe } \\
(22-46) \\
(n=351)\end{array}$ \\
\hline$\%$ spent night in hospital ${ }^{a}$ & 2.91 & 4.55 & 7.16 & 10.83 \\
\hline Odds ratio & - & 1.646 & $2.661^{*}$ & $3.942^{\dagger}$ \\
\hline Confidence interval & - & $(0.707-3.834)$ & $(1.186-5.970)$ & $(1.810-8.588)$ \\
\hline$\%$ had ED/urgent care visit ${ }^{a}$ & 9.39 & 7.95 & 11.04 & 19.09 \\
\hline Odds ratio & - & 0.763 & 0.983 & $1.807^{*}$ \\
\hline Confidence interval & - & $(0.438-1.328)$ & $(0.576-1.676)$ & $(1.109-2.965)$ \\
\hline$\%$ had outpatient visit & 35.6 & 36.65 & 34.93 & 28.77 \\
\hline Odds ratio & - & 1.175 & 1.207 & 1.014 \\
\hline Confidence interval & - & $(0.844-1.636)$ & $(0.855-1.703)$ & $(0.713-1.444)$ \\
\hline$\%$ had any $\mathrm{ADM}_{\text {care }}{ }^{a}$ & 9.39 & 12.78 & 20.3 & 26.50 \\
\hline Odds ratio & - & 1.353 & $2.202^{+}$ & $3.013^{+}$ \\
\hline Confidence interval & - & $(0.819-2.234)$ & $(1.360-3.564)$ & $(1.881-4.826)$ \\
\hline \multicolumn{5}{|l|}{$\%$ spent night in hospital } \\
\hline for $\mathrm{ADM}^{a}$ & 1.94 & 3.12 & 5.67 & 9.12 \\
\hline Odds ratio & - & 1.518 & $2.622^{*}$ & $3.918^{\dagger}$ \\
\hline Confidence interval & - & $(0.546-4.219)$ & $(1.008-6.823)$ & $(1.561-9.834)$ \\
\hline \multicolumn{5}{|l|}{$\%$ had ED/urgent care visit } \\
\hline for $\mathrm{ADM}^{a}$ & 1.94 & 3.41 & 5.97 & 14.25 \\
\hline Odds ratio & - & 1.583 & 2.520 & $6.348^{\dagger}$ \\
\hline Confidence interval & - & $(0.581-4.313)$ & $(0.980-6.481)$ & $(2.613-15.424)$ \\
\hline \multicolumn{5}{|l|}{$\%$ had outpatient visit } \\
\hline for ADM & 7.12 & 9.09 & 11.04 & 13.39 \\
\hline Odds ratio & - & 1.280 & 1.589 & $2.060^{*}$ \\
\hline Confidence interval & - & $(0.722-2.269)$ & $(0.899-2.808)$ & $(1.180-3.596)$ \\
\hline
\end{tabular}

Notes: Odds ratios are from logistic regressions of the continuous ADS score on the outcome of interest, controlling for age, gender, marital status, race/ethnicity, and years of education. ADS dependence categories are based on COMBINE quartiles. $\mathrm{ED}=$ emergency department: $\mathrm{ADM}=$ alcohol, drug, or mental health. "Indicates significant at the .05 level based on a chi-square test of association.

*Significant odds ratio at the .05 level; 'significant odds ratio at the .01 level.

did find a significantly greater adjusted OR associated with the most severe dependence category (adjusted $\mathrm{OR}=2.060$, $p<.05$ ) compared with those in the lowest dependence quartile.

Table 3 shows the proportion and adjusted ORs (relative to the lowest category) of respondents with at least one occurrence of the other economic outcomes captured on the Economic Form 90 for the four categories of dependence. Based on chi-square tests of association, we found that those with greater severity of dependence had a significantly higher probability of involvement with the criminal justice system, except for the percentage of subjects jailed or incarcerated. The logistic analyses, however, found weaker evidence of a significant relationship. For the summary measure of any involvement with the criminal justice system, we found that the highest level of dependence had a significant adjusted OR relative to the lowest level, but the intermediate two categories did not. The probability of being on parole or probation was the only subcategory of criminal justice involvement for which we found significant adjusted ORs $(p<.05)$. For this outcome, the two highest levels of severity had significant adjusted ORs (sub- stantial: adjusted $\mathrm{OR}=3.361, p<.01$; severe: adjusted $\mathrm{OR}$ $=3.901, p<.01$ ). Despite the general lack of significance from these logistic results, they still presented a consistent pattern, where greater severity was associated with greater odds of criminal justice involvement.

For automobile accidents and proportion employed, we found no consistent significant association with level of dependence. For automobile accidents, more severe dependence was associated with a greater likelihood of accidents, although this finding was not statistically significant. For employment, we also found no significant relationship based on the chi-square analysis, but the logistic analysis showed that the most severe dependence category was significantly associated with a lower probability of employment (adjusted $\mathrm{OR}=0.579, p<.05$ ). Importantly, the adjusted ORs suggested a somewhat different relationship between employment and severity of dependence than did the unadjusted sample proportions, suggesting that the relationship between dependence and employment may be confounded by demographic characteristics. Given that most results are not statistically significant, however, no firm conclusions can be drawn. Finally, among the employed subjects, those with 
TABLE 3. Proportion and odds ratios of other economic outcomes, by Alcohol Dependence Scale (ADS) categories

\begin{tabular}{|c|c|c|c|c|}
\hline \multirow[b]{2}{*}{ Outcome } & \multicolumn{4}{|c|}{ Level of dependence } \\
\hline & $\begin{array}{c}\text { Low } \\
(1-11) \\
(n=309)\end{array}$ & $\begin{array}{l}\text { Moderate } \\
(12-16) \\
(n=352)\end{array}$ & $\begin{array}{c}\text { Substantial } \\
(17-21) \\
(n=335)\end{array}$ & $\begin{array}{c}\text { Severe } \\
(22-46) \\
(n=351)\end{array}$ \\
\hline \multicolumn{5}{|l|}{$\%$ had involvement with } \\
\hline Odds ratio & - & 1.231 & 1.464 & $1.751^{*}$ \\
\hline Confidence interval & - & $(0.745-2.033)$ & $(0.897-2.398)$ & $(1.091-2.808)$ \\
\hline \multicolumn{5}{|l|}{$\%$ arrested for non-ADM } \\
\hline crimes $^{a}$ & 0.32 & 0.57 & 2.99 & 2.85 \\
\hline Odds ratio & - & 1.378 & 6.463 & 5.167 \\
\hline Confidence interval & - & $(0.123-15.498)$ & $(0.805-51.875)$ & $(0.637-41.926)$ \\
\hline$\%$ arrested for $\mathrm{ADM}$ crimes $^{a}$ & 2.27 & 4.26 & 3.28 & 6.55 \\
\hline Odds ratio & - & 1.626 & 1.109 & 1.985 \\
\hline Confidence interval & - & $(0.645-4.098)$ & $(0.414-2.966)$ & $(0.813-4.846)$ \\
\hline$\%$ had court appearance ${ }^{a}$ & 7.77 & 9.09 & 10.75 & 17.38 \\
\hline Odds ratio & - & 1.000 & 1.000 & 1.438 \\
\hline Confidence interval & & $(0.561-1.785)$ & $(0.563-1.774)$ & $(0.840-2.459)$ \\
\hline$\%$ on parole/probation ${ }^{a}$ & 2.27 & 4.83 & 8.96 & 12.82 \\
\hline Odds ratio & - & 2.012 & $3.361^{\dagger}$ & $3.901^{\dagger}$ \\
\hline Confidence interval & - & $(0.805-5.032)$ & $(1.415-7.983)$ & $(1.682-9.048)$ \\
\hline$\%$ jailed/incarcerated & 3.24 & 3.69 & 4.78 & 6.84 \\
\hline Odds ratio & - & 0.919 & 0.966 & 1.131 \\
\hline Confidence interval & - & $(0.388-2.182)$ & $(0.417-2.235)$ & $(0.510-2.504)$ \\
\hline$\%$ had automobile accident & 4.85 & 4.26 & 4.48 & 7.41 \\
\hline Odds ratio & - & 0.852 & 0.883 & 1.491 \\
\hline Confidence interval & - & $(0.406-1.789)$ & $(0.414-1.881)$ & $(0.748-2.971)$ \\
\hline$\%$ employed & 84.47 & 86.36 & 86.87 & 83.76 \\
\hline Odds ratio & - & 0.880 & 0.749 & $0.579 *$ \\
\hline Confidence interval & - & $(0.552-1.404)$ & $(0.460-1.218)$ & $(0.360-0.930)$ \\
\hline \multicolumn{5}{|l|}{$\%$ missed a day of work } \\
\hline among employed ${ }^{a}$ & 10.38 & 27.15 & 39.79 & 51.72 \\
\hline Odds ratio & - & $3.183^{\dagger}$ & $5.071^{+}$ & $7.439^{+}$ \\
\hline Confidence interval & - & $(1.964-5.157)$ & $(3.147-8.172)$ & $(4.618-11.981)$ \\
\hline
\end{tabular}

Notes: Odds ratios are from logistic regressions of the continuous ADS score on the outcome of interest, controlling for age, gender, marital status, race/ethnicity, and years of education. ADS dependence categories are based on COMBINE quartiles. $\mathrm{ADM}=$ alcohol, drug, or mental health. "Indicates significant at the .05 level based on a chi-square test of association.

*Significant odds ratio at the .05 level; ${ }^{\dagger}$ significant odds ratio at the .01 level.

higher levels of dependence were significantly more likely to report missing a day of work because of alcohol than were those with low levels of dependence.

\section{Discussion}

With the advent of the Health Insurance Portability and Accountability Act and other regulations designed to protect the confidentiality of administrative data, access to the administrative data traditionally used for economic analyses has become greatly restricted and analysts have had to rely increasingly on self-reports of economic outcomes. Despite the increasing reliance on self-report instruments, few studies have explored the ability of self-report instruments to detect differences in economic outcomes associated with differences in the severity of alcohol dependence. We used baseline data from the COMBINE trial to examine the extent to which the key economic outcome measures in the Economic Form 90 are associated with differences among individuals with varying levels of alcohol dependence. Results show that the instrument can detect differences in economic outcomes across a range of dependence severity levels. Associations were strongest for health care outcomes, but some evidence of a relationship between outcomes and alcohol dependence was found for criminal justice involvement and work absences. Based on these results, the Economic Form 90 holds promise as a potentially valid self-report instrument with which to obtain data on economic outcomes that are necessary to conduct economic evaluations. A formal test-retest reliability study, however, has not yet been performed on the Economic Form 90 .

Although we found consistent and frequently significant associations between the economic outcomes and dependence severity in the expected directions, several limitations of our analyses suggest caution when interpreting our results. First, participants in the COMBINE study met a number of fairly restrictive inclusion and exclusion criteria that may limit the generalizability of these results to less 
selected samples. Participants had to meet the Diagnostic and Statistical Manual of Mental Disorders, Fourth Edition (America Psychiatric Association, 1994), diagnostic criteria for alcohol dependence to get into the COMBINE study; therefore, this study population cannot provide a comparison with people who are not alcohol dependent, those who have a low level of dependence, or those not seeking treatment.

Second, we were unable to examine the relationship between alcohol dependence and the number of occurrences of each economic outcome, because the counts of those outcomes were too low and had insufficient variation. This may be a result of the relatively short time frame of the baseline assessment (90 days); assessing economic outcomes across a longer time frame may allow analysis of the number of occurrences of each outcome. Similarly, because many of the discrete outcomes we examined were rare events, we suspect that in many cases we failed to find a significant relationship because of a lack of statistical power. On the other hand, given the number of significance tests reported, some spurious significance is possible. Thus, we recommend readers consider the overall patterns of results rather than focus on specific tests of significance.

Finally, we did not perform a traditional psychometric assessment of the economic items in the Economic Form 90. By their very nature, objective economic outcomes do not lend themselves to scales with multiple items assessing the same construct but rather suggest single items, each asking the respondent to recall specific events. Thus, standard psychometric measures that assess the correlation of multiple items within a single construct do not apply. For this reason, analyses focused on the ability of the Economic Form 90 economic outcomes to discriminate among respondents based on their level of alcohol-dependence severity rather than to assess the reliability, validity, or internal consistency of the items in a more traditional sense.

Although our results suggest that the Economic Form 90 may be able to distinguish meaningful differences in outcomes associated with differences in the severity of dependence, the overall level of these outcomes is likely to be underestimated by the Economic Form 90. Many of the economic outcomes measured by the Economic Form 90 accumulate across months, years, or even decades. As discussed earlier, the Economic Form 90 only measures these outcomes during a 90-day interval to improve respondent recall. Therefore, to be most useful, the Economic Form 90 should be used as a repeated measure across an extended time frame. In the ancillary cost-effectiveness study of COMBINE, for example, the Economic Form 90 is administered approximately every 4 months over a 3 -year period to capture data across a much longer time frame.

Furthermore, research on reporting errors suggests that underreporting may be likely for many events (e.g., Anderson et al., 1979; Petrou et al., 2002; Ritter et al., 2001). Other research, however, suggests that reliable self-report- ing is possible for many events (Del Boca and Noll, 2000). For example, several studies have demonstrated the validity of self-reported health care use (Brown and Adams, 1992; Harlow and Linet, 1989; Jay et al., 1995; Roberts et al., 1996; Wallihan et al., 1999). Because the Economic Form 90 uses a calendar recall process and asks respondents to recall events across a relatively short time frame, the form is likely to minimize the extent of underreporting. Nonetheless, the potential for underreporting suggests that the Economic Form 90 may be most useful for assessing differences in economic outcomes across treatment groups in clinical trials when randomization makes systematic underreporting across groups unlikely. We suggest caution when using the Economic Form 90 to estimate the prevalence or extent of economic outcomes in a population, because those outcomes are likely to be underestimated.

In addition, because COMBINE uses the Economic Form 90 as part of a larger, overall assessment, we intentionally limited the economic outcomes it measures. Although we included measures of outcomes that social-costs studies identified as the key drivers of the social costs of alcohol-use disorders, many other costs also contribute to the associated economic burden. In particular, we note that medications costs are an increasing component of total health care costs but recognize that to capture medication costs accurately instruments must include detailed questions such as brand names, strength, and dose. Examples of other events with economic impact that could be considered in future economic instruments include laboratory tests, incidents of violence toward others, illegal acts such as driving under the influence that do not result in arrest, medical and psychological effects on family members, job productivity losses, and property damage not resulting from motor vehicle crashes. Furthermore, because additional detail on the outcomes that are measured by the Economic Form 90 would better support a broader range of analyses, alternative data collection instruments may be preferable if more frequent and longer patient interviews are possible. Nonetheless, we feel that the Economic Form 90 has struck a reasonable balance between collecting a range of economic outcomes and keeping respondent burden to a manageable level.

In summary, our results suggest that the Economic Form 90 is useful in assessing recent occurrence of economically relevant events at baseline and holds promise for detecting changes in economic outcomes following treatment. When combined with the results of a formal economic cost study, and with information on the opportunity costs of the economic outcomes, the Economic Form 90 will support a rigorous cost-effectiveness or cost-benefit analysis.

\section{References}

American Psychiatric Association. Diagnostic and Statistical Manual of Mental Disorders (DSM-IV), Washington, DC, 1994. 
Andersen, R., Kasper, J., and Franket, M.R. (Eds.) Total Survey Error, San Francisco, CA: Jossey Bass, 1979.

Anton, R.F., Moak, D.H., and Latham, P. The Obsessive Compulsive Drinking Scale: A self-rated instrument for the quantification of thoughts about alcohol and drinking behavior. Alcsm Clin. Exp. Res. 19: $92-99,1995$.

Anton, R.F., O’Malley, S.S., Ciraulo, D.A., Cisler, R.A., Couper, D., Donovan, D.M., Gastfriend, D.R., Hosking, J.D., Johnson, B.A., LoCastro, J.S., Longabaugh, R., Mason, B.J., Mattson, M.E., Miller, W.R., Pettinati, H.M., Randall, C.L., Swif,, R., Weiss, R.D., Williams, L.D., and Zweben, A., for the COMBine Study Research Group. Combined pharmacotherapies and behavioral interventions for alcohol dependence: The COMBINE Study: A randomized controlled trial. JAMA 295: 2003-2017, 2006.

Anton, R.F. AND SWIFT, R.M. Current pharmacotherapies of alcoholism: A U.S. perspective. Amer. J. Addict. 12 (Suppl. No. 1): S53-S68, 2003.

Brown, J.B. AND Adams, M.E. Patients as reliable reporters of medical care process: Recall of ambulatory encounter events. Med. Care 30: 400-411, 1992.

Cisler, R., Holder, H.D., and Longabaugh, R. Actual and estimated replication costs for alcohol treatment modalities: Case study from Project MATCH. J. Stud. Alcohol 59: 503-512, 1998.

COMBINE Study Research Group. Testing combined pharmacotherapies and behavioral interventions in alcohol dependence: Rationale and methods. Alcsm Clin. Exp. Res. 27: 1107-1122, 2003.

DEL BoCA, F.K. AND Noll, J.A. Truth or consequences: The validity of self-report data in health services research on addictions. Addiction $\mathbf{9 5}$ (Suppl. No. 3): S347-S360, 2000.

Dennis, M.L., Funk, R., Godley, S.H., Godley, M.D., and Waldron, H. Cross-validation of the alcohol and cannabis use measures in the Global Appraisal of Individual Needs (GAIN) and Timeline Followback (TLFB; Form 90) among adolescents in substance abuse treatment. Addiction 99 (Suppl. No. 2): 120-128, 2004.

HaRLOW, S.D. AND LINET, M.S. Agreement between questionnaire data and medical records: The evidence for accuracy of recall. Amer. J. Epidemiol. 129: 233-248, 1989.

Harwood, H., Fountain, D., and Livermore, G. The Economic Costs of Alcohol and Drug Abuse in the United States, 1992, NIH Publication No. 98-4327, Washington: Government Printing Office, 1998.

Hester, R.K. and Miller, W.R. Handbook for Alcoholism Treatment Approaches: Effective Alternatives, 3rd Edition, Boston, MA: Allyn \& Bacon, 2003.

Holder, H.D. AND BLoSE, J.O. Alcoholism treatment and total health care utilization and costs. A four-year longitudinal analysis of federal employees. JAMA 256: 1456-1460, 1986.

Holder, H.D., Cisler, R.A., Longabaugh, R., Stout, R.L., Treno, A.J., AND ZwEBEn, A. Alcoholism treatment and medical care costs from Project MATCH. Addiction 95: 999-1013, 2000.

JAY, G.M., BELLI, R.F., AND LEPKOWSKI, J.M. Quality of last doctor visit reports: A comparison of medical record and survey data. In: Proceedings of the Section on Survey Research Methods, American Statistical Association, Toronto, Canada, August 13-18, 1994, Alexandria, VA, 1995, pp. 362-367 (available at: www.amstat.org/sections/srms/ Proceedings).

Kane, R.L., Wall, M., Potthoff, S., Stromberg, K., Dal, Y., and Meyer, Z.J. The effect of alcoholism treatment on medical care use. Med. Care 42: 395-402, 2004.
Maisto, S.A., McKay, J.R., and Tiffany, S.T. Diagnosis. In: Allen, J.P. AND WILson, V.B. (Eds.) Assessing Alcohol Problems: A Guide for Clinicians and Researchers, 2nd Edition, NIH Publication No. 03-3745, Bethesda, MD: National Institute on Alcohol Abuse and Alcoholism, 2003, pp. 55-73.

Miller, W.R. and Del. BocA, F.K. Measurement of drinking behavior using the Form 90 family of instruments. J. Stud. Alcohol, Supplement No. 12, pp. 112-118, 1994.

Miller, W.R., Tonigan, J.S., and Longabaugh, R. The Drinker Inventory of Consequences (DrinC): An Instrument for Assessing Adverse Consequences of Alcohol Abuse (Test Manual). NIAAA Project MATCH Monograph Series, Vol. 4, NIH Publication No. 95-3911, Bethesda, MD: National Institute on Alcohol Abuse and Alcoholism, 1995.

Miller, W.R., Walters, S.T., and Bennet, M.E. How effective is alcoholism treatment in the United States? J. Stud. Alcohol 62: 211-220, 2001.

Petrou, S., Murray, L., Cooper, P., and Davidson, L.L. The accuracy of self-reported healthcare resource utilization in health economic studies. Int. J. Tech. Assess. Hlth Care 18: 705-710, 2002.

Project MATCH Research Group. Matching alcoholism treatments to client heterogeneity: Treatment main effects and matching effects on drinking during treatment. J. Stud. Alcohol 59: 631-639, 1998.

Ritter, P.L., Stewart, A.L., Kaymaz, H., Sobel, D.S., Block, D.A., and LORIG, K.R. Self-reports of health care utilization compared to provider records. J. Clin. Epidemiol. 54: 136-141, 2001.

Roberts, R.O., Bergstralh, E.J., Schmidt, L., and Jacobsen, S.J. Comparison of self-reported and medical record health care utilization measures. J. Clin. Epidemiol. 49: 989-995, 1996.

Saxon, A.J., Kivlahan, D.R., and Donovan, D.M. Further validation of the Alcohol Dependence Scale (ADS) as an index of severity (abstract). Alcsm Clin. Exp. Res. 29 (5 Suppl.): 31A, 2005.

Scheurich, A., Mũller, M.J., Anghelescu, 1., Lörch, B., Dreher, M., Hautzinger, M., And Szegedi, A. Reliability and validity of the Form 90 interview. Europ. Addict. Res. 11: 50-56, 2005.

SkInNER, H.A. And Al.len, B.A. Alcohol dependence syndrome: Measurement and validation. J. Abnorm. Psychol. 91: 199-209, 1982.

Skinner, H.A. And Horn, J.L. Alcohol Dependence Scale: Users Guide. Toronto, Canada: Addiction Research Foundation, 1984

SoBelL, L.C. AND SOBELL, M.B. Alcohol consumption measures. In: AlLEN. J.P. And WiLson, V.B. (Eds.) Assessing Alcohol Problems: A Guide for Clinicians and Researchers, 2nd Edition, NIH Publication No. 033745, Bethesda, MD: National Institute on Alcohol Abuse and Alcoholism, 2003, pp. 75-99.

Tonigan, J.S., MiLler, W.R., And Brown, J.M. The reliability of Form 90: An instrument for assessing alcohol treatment outcome. J. Stud. Alcohol 58: 358-364, 1997.

Wallihan, D.B., Stump, T.E., and Callahan, C.M. Accuracy of self-reported health services use and patterns of care among urban older adults. Med. Care 37: 662-670, 1999.

Westerberg, V.S., Tonigan, J.S., and Miller, W.R. Reliability of Form 90D: An instrument for quantifying drug use. Subst. Abuse 19: 179 189, 1998.

Zarkin, G.A., Bray, J.W., Davis, K.L., Babor, T.F., and Higgins-Biddle, J.C. The costs of screening and brief intervention for risky alcohol use. J. Stud. Alcohol 64: 849-857, 2003.

Zarkin, G.A., Bray, J.W., Mitra, D., Cisler, R.A., and Kivlahan, D.R. Cost methodology of COMBINE. J. Stud. Alcohol, Supplement No. 15 , pp. 50-55, 2005. 